\title{
Design and Execution of Fixture to Perform Slitting Operation On Feed Gear Shift Fork Component In Fn2 Milling Machine
}

\author{
Uddandapu Pradeep Kumar ${ }^{1}$, P.Sreenivas ${ }^{2}$, S.Mallikarjuna Reddy ${ }^{3}$ \\ ${ }^{I}$ (Asst Professor,Mechanical Engineering Department,K.S.R.M Engineering college,JntuA university,A.P, India) \\ ${ }_{2}^{2}$ (Asst Professor,Mechanical Engineering Department, K.S.R.M Engineering College JntuA university,A.P,India) \\ ${ }_{3}^{3}$ (Asst Professor,Mechanical Engineering Department, K.S.R.M Engineering College, JntuA university,A.P, \\ India)
}

\begin{abstract}
Design and execution of fixture to perform slitting operation on feed gear shift fork component in FN2 milling machine task is to design fixture for the component Feed gear fork used in radial drilling machines for gear engaging purpose. The report begins with the description of classification of fixture. This is followed by detail description of various components employed in the designing of the fixture. Details of the machine used have been provided, supplemented by diagram. It include information about the various products manufactured and also the various branches working in India. Relevant part diagrams have been included apart from the machine photograph. The criteria for this design prove are accuracy, positive locations, repeatability, production rate, and importantly the reliability under the action of the fatigue forces experienced. The clamping constructions have also been accounted for the proposed design. The proposed designs were then checked for safety under the action of the involved stresses. The calculation of the cutting forces has been showed and proved that the forces at various vital points in the design are well below the safety limits.
\end{abstract}

Keywords: Design,fixtures ,base plate,Catia V5 R16,Modelling,FN2 milling Machine (10 Italic)

\section{Introduction}

In this chapter basic concepts of fixtures are briefly discussed and problem for present work is defined.

1.1 Fixtures

Definition of Fixtures:

A fixture may be defined as a device that holds and locates a work piece. The fixture does not guide the tool.

1.2 Types of fixtures

$>$ Milling Fixture

$>$ Lathe and turret lathe fixture

$>$ Boring fixture

$>$ Tapping fixture

$>$ Turning fixture

$>$ Welding fixture

$>$ Assembly fixture

\subsection{Materials used in fixtures}

Fixtures are made of variety of materials some are hardened to resist wear. It is sometimes necessary to use on ferrous metals like phosphor, bronze to reduce wear of matting or use of nylon or fibers to prevent damage to work pieces some of the materials, which are used in fixture.

Mild steel: is issued for the most of the parts in the fixtures. Mild steel contains less than $0.25 \%$ of carbon and the content of manganese varies from $0.1 \%$ to $0.8 \%$ these steels can also be case hardened.

Cast Iron: It is used for odd shapes to save machining and laborious fabrication. By casting the cast iron with stands vibration hence is used for bases and bodies of milling fixture.

Nylon and fiber: These are used for soft lining for clamps to prevent damage of the work piece due to clamping pressure. Nylon or fiber pads are screwed or stuck to mild steel clamps.The fixtures are economical means to produce repetitive type of work by incorporating special work holding and tool guiding devices.

The following are the advantages of fixtures in mass production work.

$>$ It eliminates the marking out, measuring, and other setting methods before machining.

$>$ It increases the machining accuracy, because the work piece is automatically located and the tool is guided without making any manual adjustment. 
$>$ It enables production of identical parts, which are interchangeable. This facilitates the assembly operation.

$>$ It increases the production capacity by enabling a number of work pieces to be machined in the single setup, and in some cases a number of tools may be made to operate simultaneously.

$>$ It reduces the operator's labour and consequent fatigue as the handling operations are minimized and simplified.

$>$ It reaches semi-skilled operator to perform the operations as the setting operations of the tool and the works are mechanized. This saves labour cost.

$>$ It reduces the expenditure on the quality control of the finished products.

$>$ It reduces the overall cost of machining by fully or partly automating the processes.

\section{Elements of fixtures}

BASE PLATE

It absorbs forces arising due to vibration effect and chatter. It is usually made of mild steel plate.

Clamping Devices :A fixture may have one or more clamping devices to clamp the work piece rigidly against all disturbing forces. Some of the clamping devices used are strap clamp, screw clamp, hinged clamp, c-clamp, edge clamp, groove clamp etc

\section{Location and positioning of Elements}

The excessive thrust of the cutter must be resisted by a fixer stop because clamping device alone may not be sufficient to accomplish it.

\section{Locating System}

The locating system is used be in conjunction with the clamping system to completely constraining the work piece or eliminate as many of the six degree of freedom as are necessary for the operations to be completed with the required accuracy.

Types of Location

$>$ Cylindrical location

$>$ Six point location

\section{Design Consideration Of Fixture}

The following 'are the major factors to be considered by the designer while designing a fixture.

$>$ The quality of the part to be produced.

$>$ The quantity of the part to be produced.

$>$ The machine required for the operation.

$>$ Safety of the operator.

$>$ Weight of material.

$>$ Cost of the project.

Before design the fixture the designer should study the work piece thoroughly and he should design a fixture for the type of work with all facilities. Considering deeply the design of the fixture the designer should:

$>$ Select proper clamping arrangements.

$>$ Select proper indexing devices.

$>$ Study the rigidity and vibration problem.

$>$ Select proper table fixing arrangements.

$>$ Study proper methods of manufacturing the fixture base, body and other components.

$>$ Retrieval of the components from the fixture.

2.1 Specification of FN2 milling machine

\section{Machine Specifications}

\begin{tabular}{|c|c|c|c|}
\hline Table & Horizontal & Universal & Vertical \\
\hline Over all dimension (length*width) mm & & $1350 * 310$ & \\
\hline Clamping area (length*width) $\mathrm{mm}$ & & $1520 * 310$ & \\
\hline . Number and width of T slots $\mathrm{mm}$ & & 3-16 & \\
\hline Centre distance between $\mathrm{T}$ slots $\mathrm{mm}$ & & 65 & \\
\hline Power operated longitudinal traverse $\mathrm{mm}$ & & 800 & \\
\hline Power operated cross traverse $\mathrm{mm}$ & & 265 & \\
\hline Power operated vertical traverse $\mathrm{mm}$ & & 400 & \\
\hline Minimum distance left hand end to centre of milling spindle $\mathrm{mm}$ & & 250 & \\
\hline Swivel of table to either side degrees & & 45 & \\
\hline Maximum safe weight on table kg & 350 & 250 & 350 \\
\hline
\end{tabular}

\begin{tabular}{|l|l|l|l|}
\hline Milling spindle & Horizontal & Universal & Vertical \\
\hline Number of speeds & & 18 & \\
\hline
\end{tabular}


Design and Execution of Fixture to Perform Slitting Operation On Feed Gear Shift Fork Component..

\begin{tabular}{|l|l|l|l|}
\hline Speed range rpm & & $35.5-1000$ & \\
\hline Diameter of front bearing mm & & 85.725 & \\
\hline $\begin{array}{l}\text { Spindle nose }: \text { 1) standard ISO } \\
\text { 2) upon request ISO }\end{array}$ & & 40 & \\
\hline $\begin{array}{l}\text { Swivel of milling head to either side } \\
\text { degrees }\end{array}$ & & & 40 \\
\hline Vertical quill movement & & & 70 \\
\hline
\end{tabular}

\begin{tabular}{|l|l|l|l|}
\hline \multicolumn{1}{|c|}{ Feeds } & Horizontal & Universal & Vertical \\
\hline Number of feeds & & $\mathbf{1 8}$ & \\
\hline Feed range: (1) longitudinal and & & $16-800$ & \\
Cross mm/min & & $4-200$ & \\
(2) vertical mm/min & & & \\
\hline
\end{tabular}

Rapid rate

(1) Longitudinal and cross $\mathrm{mm} / \mathrm{min}$

2) Vertical

\section{0}

800

\begin{tabular}{|l|c|c|}
\hline Power & Horizontal universal & Vertical \\
\hline main motar kw/rpm & $5.5 / 1500$ & \\
\hline Feed motar kw/rpm & $1.5 / 1500$ & \\
\hline
\end{tabular}

\begin{tabular}{|c|c|c|c|}
\hline Space Required & Horizantal & universal & Vertical \\
\hline Length * Width ${ }^{*}$ Heigth & $257^{*} 220^{*} 207$ & $257 * 284 * 207$ & $257 * 192 * 197$ \\
\hline Weigth & Horizantal & Universal & vertical \\
\hline Net/gross approx kg & $2400 / 3200$ & $2500 / 3300$ & $2500 / 3350$ \\
\hline
\end{tabular}

\subsection{Descriptions:}

Stream lined construction, rugged and vibration free $-5.5 \mathrm{kw}$ motar for heavy stock removal -power operated feeds and rapid traverse in all directions - independent feed drive motar -wide range of spindle speeds and feeds upto $1800 \mathrm{rpm}$ and feeds-up to $800 \mathrm{~mm} / \mathrm{min}$-all operations controlled with effortless ease by pushing buttons-inching push button for speed and feed drives

\subsection{Calculations of loads}

\section{Design Analysis}

(1) Weight of collets:

Material used: Spring Steel

Weigth of each collet $=260 \mathrm{gm}$

Weight of two collets $=260 * 2=520 \mathrm{gms}$

$$
\begin{aligned}
& =0.52 \mathrm{kgs} \\
& =0.52 * 9.81=5.1012 \mathrm{~N}
\end{aligned}
$$

\section{2) weight of locking Nuts:}

(Assuming Materials used as C-45)

Weight Volume $=$ Specific weight $*$ Volume

Where volume $=$ Area $*$ Length (or) Height

$$
\begin{aligned}
& =\pi / 4 * 8 *\left(30^{2}-20^{2}\right)=3141.5926 \mathrm{~mm}^{3} \\
& =3.146 * 10^{6} \mathrm{~m}^{3}
\end{aligned}
$$

Specific weigth of C-45 material $=78400 \mathrm{~N} / \mathrm{m}^{3}$

Weight of locking nut $=78400 * 3.1416 * 10^{6}$

$$
=0.2463 \mathrm{~N}
$$

Weigth of 2 locking nuts $=0.2463 * 2=0.4926 \mathrm{~N}$

(3)Weight of Eccentric shaft bushes:

Volume $=$ Area $*$ Height $=\pi / 4\left(20^{2}-14^{2}\right) * 20=304.4245 \mathrm{~mm}^{3}$

Specific weight of C-45 $=78400 \mathrm{~N} / \mathrm{m}^{3}$

$$
\begin{aligned}
\text { Weight of eccentric ring } & =\text { specific weight } * \text { volume } \\
& =78400 * 3.2044 * 10^{-6} \\
& =0.2512 \mathrm{~N}
\end{aligned}
$$

Weight of two Eccentric shaft bushes $=0.2512 * 2$

$$
=0.5024 \mathrm{~N}
$$


Specific weight of C- $45=78400 \mathrm{~N} / \mathrm{m}^{3}$

Volume $=$ Area $*$ Height $=\pi / 4\left(20^{2}-14^{2}\right) * 20=304.4245 \mathrm{~mm}^{3}$

4) Weight of Eccentric rings

\begin{tabular}{|c|c|}
\hline Volume & $\left(\pi / 4 * 10^{2} * 10\right)+\left(\pi / 4 *\left(22^{2}-16^{2}\right) *\right.$ \\
\hline$=$ & $4008.6722 \mathrm{~mm}^{3}$ \\
\hline$=$ & $4.0087 * 10^{-6} \mathrm{~m}^{3}$ \\
\hline Specific weight of C- $45 \mathrm{I}$ & Material $=78400 \mathrm{~N} / \mathrm{m}^{3}$ \\
\hline Weight of Eccentric ring & $\begin{array}{l}=\text { Specific weight } * \text { volume } \\
=78400 * 4.0087 * 10^{-6} \\
=0.3143 \mathrm{~N}\end{array}$ \\
\hline Weight of two Eccentric & $=0.3143 * 2$ \\
\hline Rings & $=0.6286 \mathrm{~N}$ \\
\hline
\end{tabular}

\section{Weigth of Lever Handle}

Volume

$\left.=\pi / 4 *\left(22^{2}-16^{2}\right) * 15\right)+\left(\pi / 4 * 15^{2 * 70}\right)$

$$
\begin{array}{ll}
= & \left(4 / 3 * \pi^{*} 6^{2}\right) \\
= & 15206.8792 \mathrm{~mm}^{3} \\
= & 1.5207 * 10^{-5} \mathrm{~m}^{3}
\end{array}
$$

\begin{tabular}{|c|c|c|}
\hline Volume & $\begin{array}{l}= \\
= \\
=\end{array}$ & $\begin{array}{l}\pi / 4 *\left(30^{2}-20^{2}\right) * 16 \\
6283.1853 \mathrm{~mm}^{\prime} \\
6.2832 * 10^{-6} \mathrm{~m}^{3}\end{array}$ \\
\hline Specific weight of C-45 & & \\
\hline Material & $=$ & $78400 \mathrm{~N} / \mathrm{m}^{3}$ \\
\hline Weight of distance & $=$ & Specific weight $*$ volume \\
\hline Ring & & $\begin{array}{ll}= & 78400 * 6.28328 * 10^{-6} \\
= & 0.4926 \mathrm{~N}\end{array}$ \\
\hline Weight of two d & $=$ & $0.4926 * 2$ \\
\hline Ring & $=$ & $0.9852 \mathrm{~N}$ \\
\hline
\end{tabular}

Weight of lever handle $=78400 \mathrm{~N} / \mathrm{m}^{3}$

6. Weigth of distance rings

7)Weight of eccentric lock nuts

Volume

$$
\begin{array}{ccc}
= & \boldsymbol{\pi} / 4 & \left(20^{2}-10^{2}\right) * 6 \\
= & 1413.7167 \mathrm{~mm}^{3} \\
= & 1.4137 * 10^{-6} \mathrm{~m}^{3}
\end{array}
$$

Specific weight of C-45 $=78400 \mathrm{~N} / \mathrm{m}^{3}$ material

Weight of Eccentric lock nut $=$

Specific weight $*$ Volume $=78400 * 1.4137 * 10^{-6}$

Weight of two Eccentric lock $=0.1108 * 2$

Nuts $\quad=0.2217 \mathrm{~N}$

8) Weight of fixture side plates

Volume

Specific Weight of C-45

Material

Weight of side plate

Weight of two fixture side

Plates

$\begin{array}{ll}= & (1 * \mathrm{~b} * \mathrm{t})-\left(\pi / 4 * \mathrm{D}^{2} * \mathrm{~h}\right) \\ = & (75 * 70 * 20)-\left(\pi / 4 * 25^{2} * 20\right) \\ = & 95182.5229 \mathrm{~mm}^{3} \\ = & 9.5182 * 10^{-5} \mathrm{~m}^{3} \\ = & 78400 \mathrm{~N} / \mathrm{m}^{3} \\ = & \\ = & \text { specific weight } * \text { volume } \\ = & 78400 * 9.5182 * 10^{-5} \mathrm{~m}^{3} \\ = & 7.4623 \mathrm{~N} \\ = & \\ & \end{array}$


9) Weight of fixture plate (where component is placed)

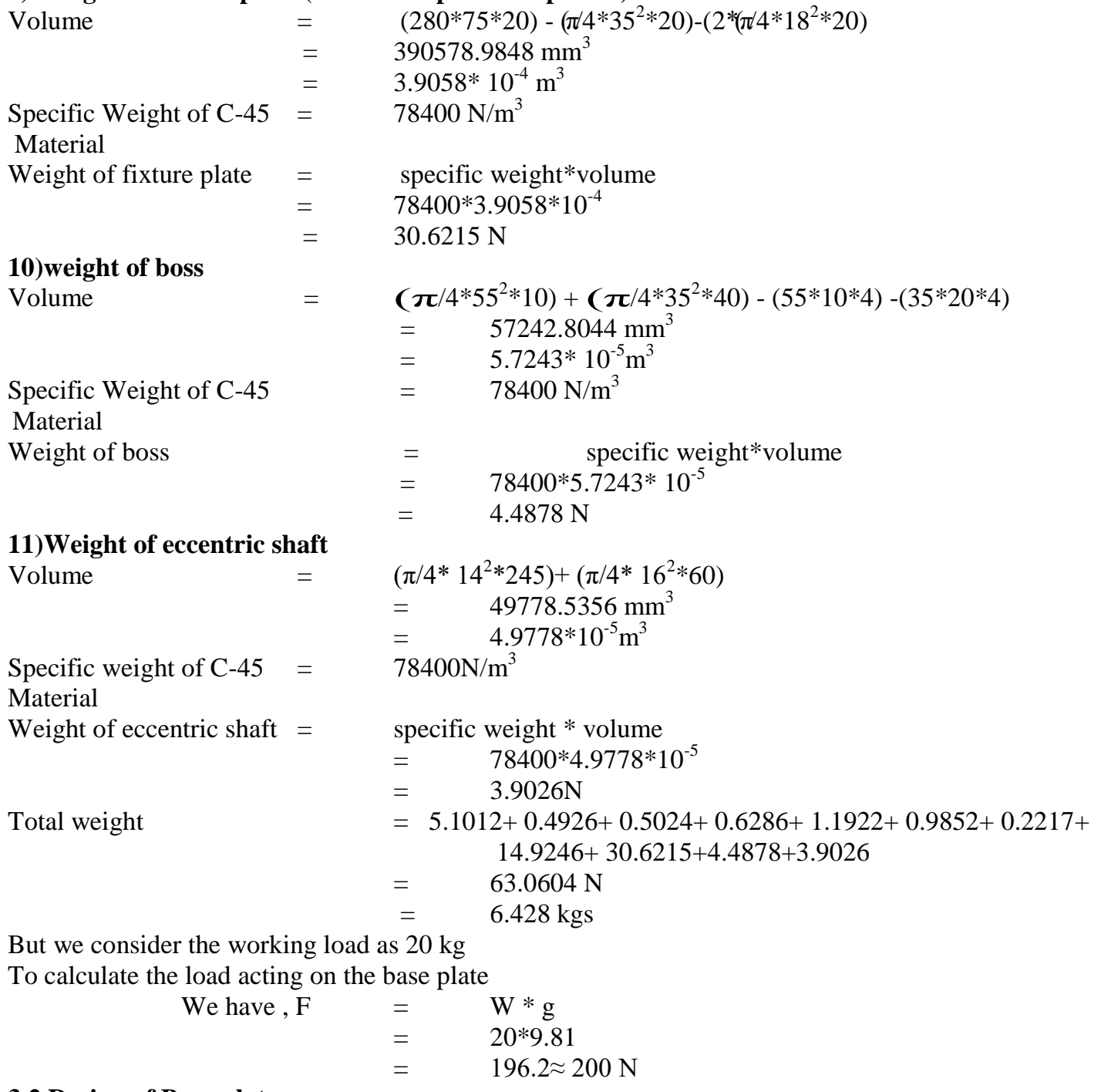

\subsection{Design of Base plate}

Assumptions for base plate:

(a) Design for static load.

(b) Design for dynamic load,

(a) Static load

$\begin{aligned} \text { Working load } & = & \text { factor of safety } * \text { static load } \\ & = & 3.0 * 200 \\ & = & 600 \mathrm{~N}\end{aligned}$

Working load $=0.6 \mathrm{KN}$

Since the load tends to compress the component, therefore compressive stress is developed.

$$
\begin{aligned}
\sigma_{(\mathrm{S})} & =\sigma_{(\text {yield }) / F . O . S} \\
& =353 / 3 \quad\left(\text { for C-45 }: \sigma_{\mathrm{y}}=353 \mathrm{Mpa}\right) \\
& =117.667 \approx 118 \mathrm{Mpa} \text { (or) } 118 \mathrm{~N} / \mathrm{mm}^{2}
\end{aligned}
$$

Stress induced in base plate

Stress on base plate $\quad=$ total weight acting on the base plate / area of the base plate

$=\underline{\text { weight of component }+ \text { weight of fixture parts on base plate }}$

$$
\begin{aligned}
& =(14.715+63.0604) /(75 * 35 * 2) \\
& \text { Area of the base plate }
\end{aligned}
$$$$
=14.814 * 10^{-3} \mathrm{~N} / \mathrm{mm}^{2}
$$

Since the stress induced in the base plate is less than the allowable stress, hence the design of the base plate is safe 


\section{Dynamic load (or) Forces}

Dynamic forces are due to the cutting forces on the component

Cutting speed, $v=\pi \mathrm{DN} / 1000 \mathrm{~m} / \mathrm{min}$

The dynamic forces will be maximum in case of milling operation, as the metal removel rate is maximum in milling.

Milling cutter diameter $\mathrm{D}=150 \mathrm{~mm}$

Cutter speed $\mathrm{N}=40 \mathrm{rpm}$

Cutting speed $\mathrm{v}=\pi \mathrm{DN} / 1000$

$$
=\left(\pi^{*} 150 * 40\right) / 1000
$$

Cutting Force, $\mathrm{F}=10 \mathrm{HP} / 1$

$$
=18.85 \mathrm{~m} / \mathrm{min}
$$

$$
=0.5336 \mathrm{~N}
$$

$\mathrm{F}($ working $)=$ Factor of safety $*$ cutting force

$$
\begin{aligned}
& =3 * 0.5336 \\
& =1.6008 \mathrm{~N}
\end{aligned}
$$

Due to this load bending,stresses are developed in the base plate.

Bending stress $\sigma_{\mathrm{b}}=\mathrm{M} / \mathrm{Z}$

Now considering the dimensions obtained from static load, bending stresses are calculated.

Where $\mathrm{M}=$ bending moment $=1.6008 \mathrm{~N}$

Section modulus , $\mathrm{Z}=\left(\mathrm{b} * \mathrm{~h}^{2}\right) / 6=\left(75^{*} 208^{2}\right) / 6=540800 \mathrm{~mm}^{3}$

Bending stress, $\sigma_{(b)}=M / Z=1.6008 / 540800=2.96 * 10^{-6} \mathrm{~N} / \mathrm{mm}^{2}$

Since the stress obtained ,i.e. $2.96 * 10^{-6} \mathrm{~N} / \mathrm{mm}^{2}$ is less compared to permissible stress $118 \mathrm{~N} / \mathrm{mm}^{2}$

Hence the design is safe.

\section{Cost Analysis}

Machine hour rate $=($ Investment on machine cost + Interest rate + cost of average standard tools + cost of average maintenance +Incentive cost + energy (electricity charges)+ remaining overhead charges)

Machine hour rate of FN2 milling machine $=150 \mathrm{Rs} / \mathrm{hr}$.

\subsection{Cost of slitting operation of component (Existing method)}

On FN2 milling machine:

Machining time $=12 \mathrm{~min}=0.2 \mathrm{hr}$

Total cost of machining $=0.2 * 150=$ Rs 30 Per component.

Standard setting time for shift quantity (20 no's per shift)

In FN2 milling Machine $=45 \mathrm{~min} / \mathrm{batch}=0.75 \mathrm{hr} / \mathrm{shift}$

$$
=0.75^{*} \text { Rs. } 150=\text { Rs. } 112.5 \text { Per shift }
$$

Set up cost $=$ Rs.5.625/component

Total cost per component $=$ Machining cost + setup cost $=30+5.625=$ Rs. $35.625 /$ component

For 1000 components $=$ Rs.35,625/-

\subsection{Cost of slitting operation of component (New method).}

Machine hour rate $=150 \mathrm{Rs} / \mathrm{hr}$.

Machining time $=6 \mathrm{~min}=0.1 \mathrm{hr}$

Total cost of machining $=0.1 * 150=$ Rs 15 Per component

Standard setting time for shift quantity (20 No's)

Setup cost $=$ Rs.5.625/component.

Total cost per component $=$ machining cost + setup cost

$$
=15+5.625=\text { Rs. } 20.625 / \text { component }
$$

For 1000 components $=20.625 * 1000=$ Rs. $20,625 /$ -

Net saving $=$ cost for existing method - cost for New method

$$
=35,625-20625
$$

=Rs. $15,000 /$ - for 1000 components

Net saving $=$ Rs.15 Per component

\subsection{Number of components machined(Existing Method)}

\section{Production Analysis}

On FN2 milling machine:

Setting time $=45 \mathrm{~min} / \mathrm{batch}$

Machining time $=12 \mathrm{~min} /$ component 
Total machining time $=45+12 * \mathrm{X}$

$\mathrm{X}$-Number of components machnined

The Total number of components machined per shift

Total Machining time $=6 \mathrm{hr}$

$360=45+12 * X$

$$
=360 \mathrm{~min}
$$

$\mathrm{X}=(360-45) / 12=315 / 12=26.25=26$

26 components can be machined by the existing method

\subsection{Number of components machined (NEW METHOD)}

On FN milling machine

Setting Time $=45 \mathrm{~min}$

Machining time $=6 \mathrm{~min}$

Total machining time $=45+6=51 \mathrm{~min}$ per component

Therefore the number of components machined per shift: Per shift, total maching time $=45+6 * X$

Where $\mathrm{x}$ is number of components machined

$360=45+6 * \mathrm{X}$

$\mathrm{X}=(360-45) / 6$

$\mathrm{X}=315 / 6$

$\mathrm{X}=52.5=53$

53 components can be machined by the new method

By New method (27) more number of components can be machined per shift.

\section{Conclusion}

The Deficiencies noted in the existing process of manufacturing feed gear shift fork component can be overcome by the designing and executing the rigid fixture.

Use of fixture which was designing and executed has got following advantages over earlier jobbing method

$>$ By the design and manufacture of fixture the operation time is reduced

$>$ Instead of skilled labourers,semiskilled laborers can be employed

$>$ Since the positioning accuracy is pre-determined the inter changeability is easy

$>$ Loading and unloading of the components is feasible

$>$ Operators fatigue life is less because easy handling of the part

$>$ Consistency in the product quality

$>$ Ideal cycle time is reduced

$>$ Productivity increases and hence profitability

\section{Reference books}

\section{Bibliography}

[1]. W.E Boyes,jigs and fixtures, society of manufacturing engineering Michigan

[2]. S.K. Hajra Choudhury,workshop technology,Asia publishing home 1976

[3]. R.K.Jain,Production technology,Khanna publishers, $18^{\text {th }}$ edition

[4]. Edward.G. Hoffman,Jigs and Fixtures,sixth edition, McGraw-Hill Inc,1973

[5]. R.S.Khurmi and Bhavikatti,Strength of materials

[6]. Dr.K.Lingaiah,Machine Design Data hand Book Vol-1 ,Second edition,vol-2 sixth edition,suma publishers, 1989

[7]. HMT production technology, Tata Mc Graw hill publishing company

[8]. R.S.Khurmi,J.K.Gupta,Machine Design,First Edition,Eurasia publishing House(pvt) Ltd.

[9]. N.D.BHATT and V.M PANCHAL, machine Drawing, Thirty eight edition charotar publishing house, 2003 Software

Websites manual CATIA V5R17

[10]. www.HMTindia.com, www.jigs and fixtures.com 